\title{
Colloids in Dialytic Refractory Hypotension
}

\author{
Guy Rostoker
}

Additional information is available at the end of the chapter

http://dx.doi.org/10.5772/45929

\section{Introduction}

\subsection{Definition and epidemiology of dialytic hypotension}

Intradialytic hypotension is the most common complication of hemodialysis,occurring in up to $33 \%$ of patients. There are two main clinical patterns of dialysis-associated hypotension : the first is episodic hypotension (defined by a sudden drop of systolic blood pressure below $100 \mathrm{mmHg}$ or at least $30 \mathrm{mmHg}$ with accompanying clinical symptoms), that typically occurs during the later stages of dialysis sessions and is generally favored by excessive weight gain ; the second is chronic persistent hypotension, which affects about $10 \%$ of long-term dialysis patients [1, 2], most of whom experience frequent episodes of hypotension during dialysis sessions, whereas some patients have permanent hypotension with low predialysis systolic pressure, often less than $100 \mathrm{mmHg}[3,4]$. Intradialytic hypotension not only causes discomfort and has a negative impact on health-related quality of life but it may also adversely affect the outcome of chronic hemodialysis, reducing patients' life expectancy and favoring underdialysis [5-10]. According to recent data, low pre-dialytic systolic and diastolic pressures, like low post-dialytic systolic pressure and the occurrence of hypotensive episodes during dialysis sessions, are associated with a significantly increased risk of death [5-9]. Moreover, a recent Japanese study has shown a link between dialysis-related hypotension and the occurrence of progressive frontal lobe atrophy [10]. The incidence of intradialytic hypotension is expected to grow with the increasing number of elderly and diabetic patients and patients with cardiovascular disease who are now starting hemodialysis, together with the use of long-term dialysis in an increasing number of hemodialyzed patients. In addition, dialysis treatment time has had a tendency to decrease over the last two decades and all these situations are known to be risk factors for this phenomenon $[2,3]$. 


\subsection{Etiology and pathogenesis of dialytic hypotension}

Several factors contribute to dialytic hypotension. These include too rapid fluid removal in an attempt to reach dry weight, a rapid reduction in plasma osmolality which causes extracellular water to move into cells, high interdialytic weight gain, anemia, poor nutritional status with hypoalbuminemia, autonomic neuropathy, anephric status, reduced pressor response to vasopressor agents, reduced cardiac reserve, increased arterial stiffness, impaired venous compliance, use of acetate rather than bicarbonate as a dialysate buffer, ingestion of a meal immediately before or during the dialysis session, use of low sodium or high magnesium concentrations in the dialysate, and intake before the dialysis session of anti-hypertensive medications that can impair cardiovascular stability (especially nitrate derivatives) [1-4, 11,12]. In a recent cross-sectionnal study of a cohort of 72 hemodialysis patients, 36 of whom suffered from dialysis-relatedchronic hypotension, cardiac diastolic dysfunction was found to be associated with dialysis hypotension [13]. The excessive release of several endogenous vasodilatators such as nitric oxide, adrenomedullin and adenosine, has been implicated in the pathogenesis of dialytic hypotension, together with an imbalance in the synthesis of the endogenous vasoconstrictors endothelin and vasopressin [14-17]. The immediate cause of intradialytic hypotension is acute central hypovolemia [2,4]. Frank hypotension occurs when cardiovascular mechanisms do not adequately compensate for the blood volume reduction resulting from the imbalance between the ultrafiltration rate and the plasma-refilling rate [12].

\section{Management and prevention of dialytic hypotension}

Management of intradialytic hypotension involves treating the acute episode and applying measures to prevent future episodes $[4,11,18]$. The acute management of intradialytic hypotension includes the following measures : reducing or halting ultrafiltration, use of the Trendelenburg position and often a reduction in the blood flow rate and use of volume expanders, regardless of the underlying mechanism $[4,11,18]$. Normal saline is the most widely used volume expander and has been advocated as first-line therapy for intradialytic hypotension $[4,11,18]$. Commonly used second and third-line fluids are hypertonic saline, dextran, hydroxyethyl starch (HES), mannitol, albumin and gelatin solutions $[4,11,18,19]$. Standard measures to prevent or alleviate intradialytic hypotension include accurate setting of the dry weight, avoidance of modifiable factors known to favor this phenomenon (e.g. excessively rapid fluid removal in an attempt to reach dry weight, anemia, poor nutritional status with hypoalbuminemia, ingestion of a meal immediately before or during the dialysis session, and intake before the dialysis session of anti-hypertensive medications) that can impair cardiovascular stability, adjustment of the dialysate sodium and/or calcium concentration and temperature, use of initial ultrafiltration followed by standard (or isovolemic) dialysis, use of sodium, and ultrafiltration modeling [1-4,14]. Among resistant patients, the most effective strategies to prevent intradialytic hypotension are to increase the dialysis time 
(for example by using either short daily hemodialysis sessions or frequent nocturnal hemodialysis) or to switch to peritoneal dialysis [1-4,14].

\section{Use of colloids in refractory dialytic hypotension}

Recent studies have shown that human albumin is safe in intensive care unitsand can also be useful in this setting in patients with acute renal failure secondary to sepsis or associated with profound hypoalbuminemia [20]. As central hypovolemia is the initiating factor in the pathogenesis of dialytic hypotension [2,12], recent studies have hypothesized and analyzed the potential benefit of systematic infusion of colloids -- $20 \%$ albumin or $4 \%$ gelatin -- during dialysis sessions in hypotension-prone patients unresponsive to usual preventive measures $[21,22]$. Until recently, few studies have evaluated colloids and especially albumin as a priming fluid for hemodialysis in septic patients or as preventive or curative therapy for hypotension-prone dialysis patients. Jardin and coworkers showed that infusion of $300 \mathrm{ml}$ of $17.5 \%$ albumin as a priming fluid at the start of the dialysis session resulted in better ultrafiltration and hemodynamic stability than saline infusion in patients with sepsis-induced anuric acute renal failure ; these authors also showed that hypovolemia(as reflected indirectly by reduced left ventricular filling pressure), reduced cardiac output and the decline in mean arterial pressure were better corrected by $17.5 \%$ albumin than by saline [23]. McLigeyo first reported an improvement in hemodynamic parameters in four hemodialysis patients with chronic persistent hypotension receiving systematic infusions of $100 \mathrm{ml}$ of $25 \%$ albumin [24]. More recently, Van der Sande and coworkers showed in nine cardiac-compromised hypotension-prone dialysis patients that $100 \mathrm{ml}$ of $20 \%$ albumin and $100 \mathrm{ml}$ of hydroxyethyl starch preserved systolic blood pressure and relative blood volume better than $33 \mathrm{ml}$ of $3 \%$ saline during a hypotensive episode [25]. However, the side effects of hydroxyethyl starch (prolonged bleeding time, deposition of HES in various tissues and especially the liver) preclude its use in this setting and it is now forbidden in France and in numerous countries in dialysis patients [26,27].

We recently conducted a single blind prospective cross-over study of systematic infusion of $200 \mathrm{ml}$ of $20 \%$ albumin as compared to $200 \mathrm{ml}$ of $4 \%$ gelatin in 10 patients on long-term bicarbonate hemodialysis with refractory permanent hypotension (despite cool dialysate associated with sodium and ultrafiltration profiling, at an ideal dry weight assessed by echocardiography); the study lasted 20 weeks [21]. We analyzed the effect of albumin and gelatin infusions on systolic and diastolic pressure and the number of hypotensive episodes by using the n-of- 1 trial methodology and the Wilcoxon matched-pairs signed-ranks test [21]. Statistical analysis of individual data showed that $20 \%$ albumin increased systolic pressure in 6 patients ( $p<0.05$ Wilcoxon test) whereas $4 \%$ gelatin improved systolic pressure in only 2 patients ( $\mathrm{p}<0.05$ Wilcoxon test) [21]. 


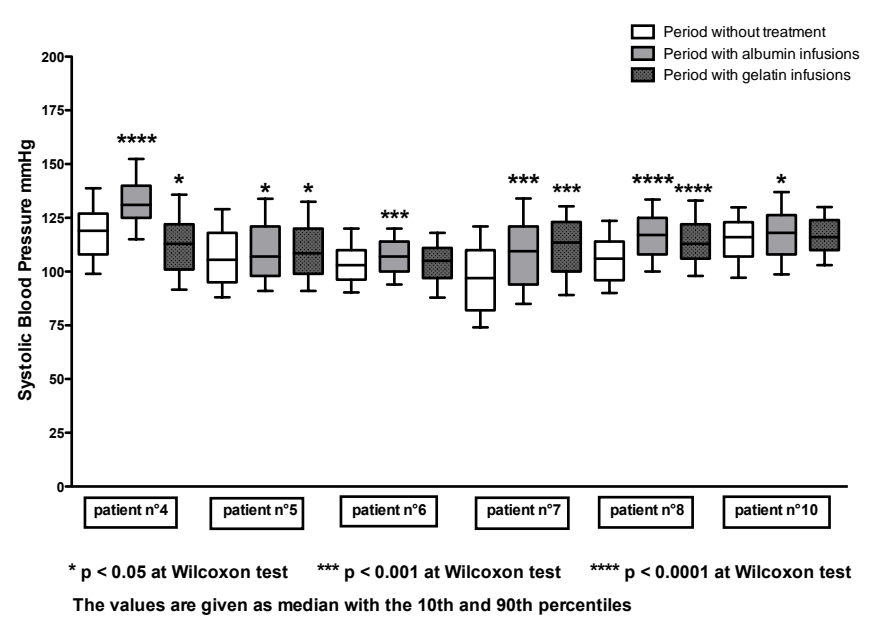

Figure 1. Evolution of systolic blood pressure with $20 \%$ albumin and $4 \%$ gelatin infusions in improved patients according toRostoker $\mathrm{G}$,et al. A pilot study of routine colloid infusion in hypotension-prone dialysis patients unresponsive to preventive measures. J Nephrol 2011; $24(02): 208-217 ;{ }^{*} p<0.5$ at Wilcoxon test, ${ }^{* * *} p<0.001$ at Wilcoxon test, $* * * * p<0.0001$ at Wilcoxon test; The values are given as median with the $10^{\text {th }}$ and $90^{\text {th }}$ percentiles

Albumin infusions increased diastolic pressure in 4 patients $(\mathrm{p}<0.05$ Wilcoxon test) whereas gelatin improved diastolic pressure in only 1 patient ( $p<0.05$ Wilcoxon test) [21].

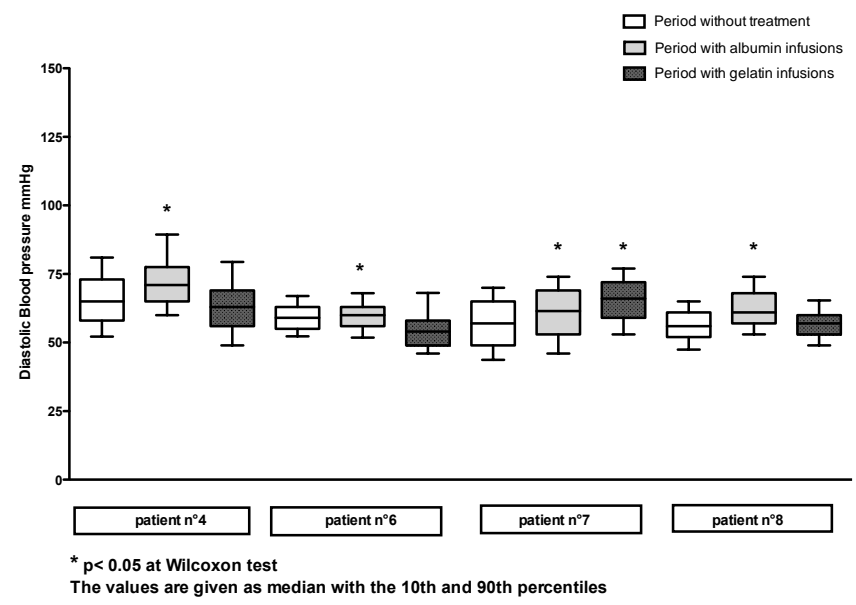

Figure 2. Evolution of diastolic blood pressure with $20 \%$ albumin and $4 \%$ gelatin infusions in improved patients accordingtoRostoker $\mathrm{G}$,et al. A pilot study of routine colloid infusion in hypotension-prone dialysis patients unresponsive to preventive measures. J Nephrol 2011; 24(02): 208-217; ${ }^{*} \mathrm{p}<0.05$ at Wilcoxon test; The values are given as median with the $10^{\text {th }}$ and $90^{\text {th }}$ percentiles 
The median number of hypotensive episodes (systolic pressure $<100 \mathrm{mmHg}$ ) fell significantly in 3 patients during 20\% albumin infusion and in 2 patients receiving $4 \%$ gelatin $(\mathrm{p}<0.05$, Wilcoxon test) [21]. Dialysis quality assessed by the Kt/V ratio and the relative blood volume reduction were also stable, whereas ionic dialysance at the end of the dialysis session was improved by albumin but not by gelatin ( $p<0.05$, repeated measure ANOVA) [21]. Thus,in this single blind cross-over pilot study using n-of- 1 methodology, we found that systematic infusion of $20 \%$ albumin or $4 \%$ gelatin during hemodialysis sessions improved hemodynamic parameters (systolic blood pressure, diastolic blood pressure and the number of hypotensive episodes) and the ultrafiltration rate in most hypotension-prone patients unresponsive to usual preventive measures [21]. Albumin was proved to be superior to gelatin; however, both colloids were ineffective in some patients, suggesting the need for careful and objective evaluation of these expensive therapeutics on an individual level [21].

\section{Hemodynamic mechanisms of action of colloids in refractory dialytic hypotension}

In hemodialysis sessions, during ultrafiltration, the refilling rate is dependent on colloid osmotic pressure [28]. Therefore, systematic infusion of $20 \%$ albumin during the dialysis session and, to a lesser extent, $4 \%$ gelatin, would be expected to increase colloid osmotic pressure, enhance plasma refilling and thus prevent an abrupt reduction in blood volume and acute hypovolemia. Albumin has a water binding capacity of $18 \mathrm{ml}$ per gram, and 200 $\mathrm{ml}$ of $20 \%$ albumin solution binds $720 \mathrm{ml}$ of water for 6-8 hours, whereas $200 \mathrm{ml}$ of $4 \%$ gelatin binds only $200 \mathrm{ml}$ of water for $4-5$ hours $[29,30]$. It is also tempting to postulate that colloids counteract the reduced cardiac preload with both atrial and ventricular underfilling as recently shown by Graziani and coworkers at the end of the ultrafiltration session in the subset of patients with severe dialysis-related hypotension [31]. Finally, systematic infusion of colloids could improve cardiac output in patients with diastolic dysfunction: the German nephrologic school postulated in the late 1980s, and demonstrated in the early 1990s, that left-ventricular hypertrophy was a risk factor for dialysis-related hypotension due to diastolic dysfunction [32-35]. In contrast to German nephrologists, we found no relationship between diastolic dysfunction and left ventricular mass [13]. The latter finding might be related to changes in the epidemiology of dialysis over the last two decades: patients in the eighties had left ventricular hypertrophy related to both hypertension and uremic fibrosing cardiomyopathy, promoted by a long history of chronic dialysis with cuprophane membranes, while dialysis patients are now older and have diabetes or cardiovascular diseases (especially ischemic cardiopathy), which are known to cause left ventricular diastolic dysfunction and diastolic heart failure [13]. In patients with a very long dialysis vintage left ventricular enlargement is attributable to chronic volume and flow overload associated with anemia, presence of arteriovenous fistulas, sodium, water and uremic toxins retention [36]. Several mechanisms are involved in the pathophysiology of dialytic hypotension secondary to cardiac diastolic dysfunction: first, diastolic dysfunction in hemodialysis patients induces 
filling disturbances in diastole leading to systolic dysfunction especially a fall in stroke volume during hypohydratation induced by rapid ultrafiltration or when plasma refilling compensatory mechanisms are deficient resulting in central hypovolemia and abrupt hypotension: central hypovolemia in such cases could be counteracted by infusions of colloids $[37,38]$. Second, these hearts have a limited ability to utilize the Franck-Starling mechanism during exercise or its counterpart such as a dialysis session. Such limited preload reserve especially if coupled with chronotropic incompetence seen with advancing age limits cardiac output during exercise and dialysis sessions ; this leads to lactate accumulation and functional abnormalities of the myocardium [37,38]. Third, a substantial number of patients who have left ventricular hypertrophy with high wall thickness and a small end diastolic volume exhibit a low stroke volume and depressed cardiac output [35].

\section{Modulation of oxidative stress and microinflammatory status by colloids in refractory dialytic hypotension}

Data on the association between inflammatory status and dialysis hypotension are scarce: Tomita and coworkers have shown in nine patients with a history of intradialytic hypotension when compared with eight patients without dialysis associated hypotension a correlation between the levels of CRP and IL6 and the maximum percent change in mean arterial pressure over multiple dialysis sessions suggesting that dialysis hypotension may trigger inflammation [39]. This is consistent with the finding of Bergamini et al who found a significant release of TNF-alpha during hypotension episodes [40]. We recently hypothesized that frequent hypotension episodes may induce a noxious inflammatory response mediated by oxidative stress induced by ischemia-reperfusion phenomenon [22]. In a prospective cross-over study (lasting 20 weeks) of routine infusion of $200 \mathrm{ml}$ of $20 \%$ albumin versus $200 \mathrm{ml}$ of $4 \%$ gelatin in 10 patients with refractory intradialytic hypotension, we analyzed the effect of $20 \%$ albumin and $4 \%$ gelatin on microinflammatory status, oxidative stress, serum nitrite and nitrate levels by analysis of variance [22]. A significant decrease in serum ceruloplasmin and serum C3 was observed during the albumin period ( $p<0.05$, repeated measure ANOVA) [22]. A significant decrease in serum hydrogen peroxide was seen during albumin and gelatin administration $(\mathrm{p}<0.01$, repeated measure ANOVA) and a dramatic decrease in serum lipid peroxides was observed during the albumin period only ( $\mathrm{p}<0.01$, Friedman test) [22].

Serum lactoferrin, serum proinflammatory cytokines and serum nitrite and nitrate levels remained stable during the different periods of this pilot trial [22]. These results strongly suggest that the improvement in microinflammatory status observed in hypotension prone dialysis patients may be related to the decrease in ischemia-reperfusion of noble organs by infusions of colloids together with a specific reduction of oxidative stress by $20 \%$ albumin. 


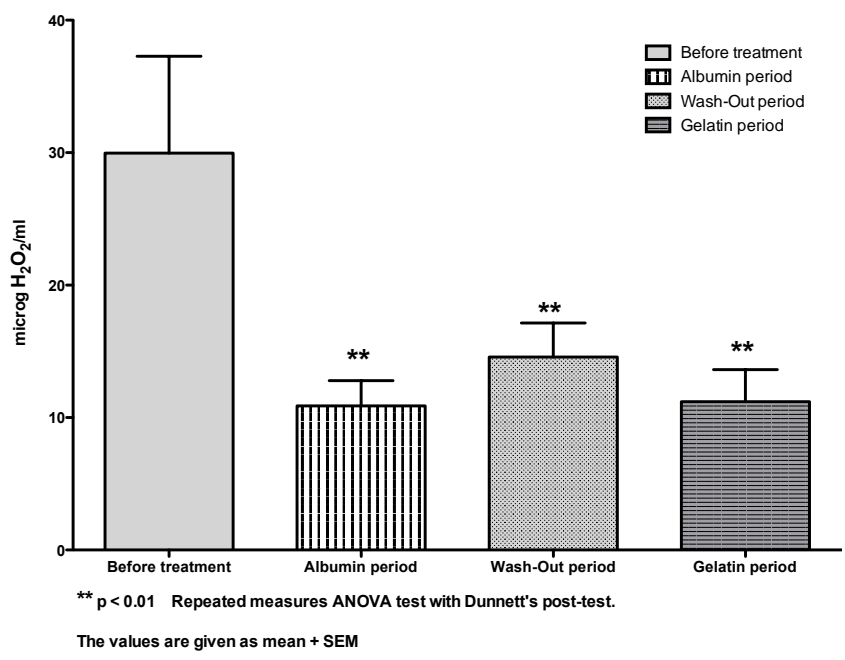

Figure 3. Concentration of serum hydrogen peroxide in patients with refractory dialytic hypotension treated by systematic infusion of colloids during dialysis sessions, according to Rostoker $\mathrm{G}$ et al Modulation of oxydative stress and microinflammatory status by colloids in refractory dialytic hypotension. BMC Nephrol 2011; oct 20; 12 (1): 58; ${ }^{* *} \mathrm{p}<0.01$ Repeated measures ANOVA test with Dunnett's post-test

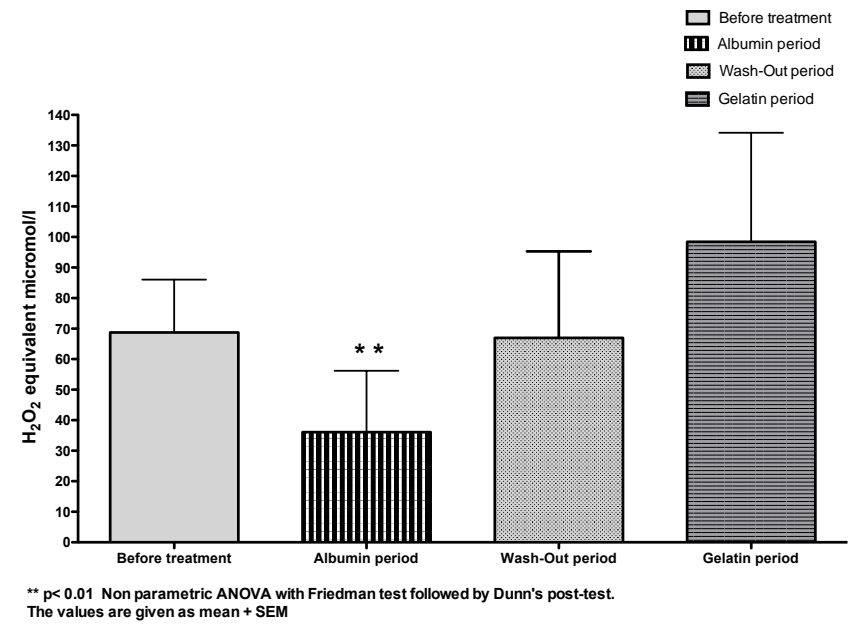

Figure 4. Concentration of serum lipid peroxides in patients with refractory dialytic hypotension treated by systematic infusion of colloids during dialysis sessions, according to Rostoker $\mathrm{G}$ et al Modulation of oxydative stress and microinflammatory status by colloids in refractory dialytic hypotension. BMC Nephrol 2011; Oct 20; 12 (1): 58 ; ${ }^{* *} p<0.01$ Non parametric ANOVA with Friedman test followed by Dunn's post-test.; The values are given as mean + SEM 


\section{Anti-inflammatory mechanisms of action of colloids in refractory dialytic hypotension}

In the aforementioned pilot study, C3 and ceruloplasmin were significantly lowered during the albumin period but not during the gelatin period [22]. This is consistent with recent studies using experimental models of hemorrhagic shock, which indicated that the type of resuscitation fluid greatly influences proinflammatory responses and especially neutrophil activation and nuclear factor-Kappa B gene transcription; albumin was found to be the least proinflammatory fluid [41, 42]. Conversely, ex-vivo data suggest that uremia may also increase vascular permeability [43] which may be acutely raised during dialysis-associated hypotension via released mediators such as adenosine aimed to preserve perfusion of the noble organs [17]; in this setting, albumin may itself influence vascular integrity by binding to the interstitial matrix and sub-endothelium and by altering the permeability of these layers to large molecules and solutes; these effects may be mediated by the binding of arachidonic acid to albumin and by polynitroxylated albumin, which inhibits xanthine-oxidasemediated adhesion of human neutophils to endothelial cells [44].

In this trial, serum hydrogen peroxide levels were significantly lowered during both the albumin and the gelatin periods, suggesting that the improvement in hemodynamic parameters by colloids reduces oxidative stress related to the ischemia-reperfusion of noble organs that occurs during dialytic hypotension [22,45]. Besides this classical ischemia-reperfusion mechanism, by analogy with heart failure, it was hypothesized that entry of bacterial endotoxin during dialysis sessions might be the result of intermittent underperfusion of the intestine during dialysis-associated hypotension episodes leading to cardiac stunning and oxydative stress $[46,47,48]$; thus in this setting, colloids may improve both systemic and intestinal perfusion and reduce gut ischemia $[22,46,47,48]$. In the latter pilot study, serum lipid peroxide levels were also significantly reduced only during the albumin period. This is consistent with data showing that human serum albumin and bovine serum albumin provide protection from lipid peroxidation propagated by inorganic reactive oxygen species generated from xanthine oxidase/hypoxanthine in artificial systems [49] and that persistent hypoalbuminemia in hemodialysis patients is associated with peroxidation of erythrocyte membranes [50]. Moreover, albumin is the major extracellular source of reduced sulphydryl groups, termed thiols which are avid scavengers of reactive oxygen and nitrogen species;inthis way albumin influences redox balance $[51,52]$. All these data also strongly suggest that dialytic hypotension may contribute by different ways to the overproduction of reactive oxygen species seen in end-stage renal failure patients, a multifactorial process mainly related to uremia per-se, the hemoincompatibility of the dialysis system and trace amounts of endotoxin in the dialysate, gut ischemia and that colloids may indifferent mechanisms counteract it $[22,53]$. 


\title{
7. Conclusions
}

Recent studies have shown that systematic infusions of $20 \%$ albumin and $4 \%$ gelatin during hemodialysis sessions improve hemodynamic parameters and ultrafiltration rate in most hypotension prone dialysis patients unresponsive to the usual preventive manoeuvers. An improvement in microinflammatory status was observed in parallel, which might be related to the decrease in both ischemia-reperfusion of noble organs, gut ischemia and oxidative stress. Hyperoncotic $20 \%$ albumin was found to have greater anti-inflammatory and anti-oxidative properties than $4 \%$ gelatin. Moreover, in the case of a new and expensive therapy such as $20 \%$ albumin (cost of $200 \mathrm{ml} 20 \%$ albumin : 80 Euros as compared to 4 Euros for 200 $\mathrm{ml} 4 \%$ gelatin, in France), n-of-1 trials can furnish powerful evidence for provision on an individual basis, allaying managerial and medical fears as to the cost of frequently ineffective therapies being applied to an expanding at-risk population. From a pragmatic point of view, we advise practitioners to initiate first gelatin which is much less expensive when a treatment of systematic infusion of colloids is scheduled during dialysis sessions. Owing to its high cost, hyperoncontic albumin should be considered as a second-line therapy.Further well-designed controlled trials with a sufficient number of patients, of hyperoncotic $20 \%$ albumin and $4 \%$ gelatin in hypotension-prone dialysis patients are warranted to assess the benefit of colloids infusions in dialytic refractory hypotension.

\section{Author details}

\author{
Guy Rostoker*
}

Address all correspondence to: rostotom@orange.fr

Service de Néphrologie et de Dialyse, Hôpital Privé Claude Galien, Quincy Sous Sénart, France

\section{References}

[1] Leunissen KM, Kooman JP, Van Kuijk W, et al. Preventing haemodynamic instability in patients at risk for intra-dialytic hypotension. Nephrol Dial Transplant 1996; 11(Suppl 2): 11-15

[2] Sulowicz W, Radziszewski A. Pathogenesis and treatment of dialysis hypotension. Kidney Int 2006; 70: S36-S39

[3] Tislér A, Akócsi K, Hárshegi I, et al. Comparison of dialysis and clinical characteristics of patients with frequent and occasional hemodialysis associated hypotension. Kidney Blood Press Res 2002; 25: 97-102 
[4] Zucchelli P, Santoro A. The management of hypotension in dialyzed patients. Miner Electrolyte Metab 1999; 25: 105-108

[5] Iseki K, Miyasato F, Tokuyama K, et al. Low diastolic blood pressure, hypoalbuminemia and risk of death in a cohort of chronic hemodialysis patients. Kidney Int 1997; 51: $1212-1217$

[6] Zager P, Nikolic J, Brown R, et al. "U" curve association of blood pressure and mortality in hemodialysis patients. Kidney Int 1998; 54: 561-569

[7] Port FK, Hulbert-Shearon TE, Wolfe RA, et al. Predialysis blood pressure and mortality risk in a national sample of maintenance hemodialysis patients. Am J Kidney Dis 1999; 33: 507-517

[8] Shoji T, Tsubakihara Y, Fujii M, Imai E. Hemodialysis-associated hypotension as an independent risk factor for two-year mortality in hemodialysis patients. Kidney Int 2004; 66: 1212-1220

[9] Tislér A, Akócsi K, Borbás B, et al. The effect of frequent or occasional dialysis-associated hypotension on survival of patients on maintenance hemodialysis. Nephrol Dial Transplant 2003; 18: 2601-2605

[10] Mizumasa T, Hirakata H, Yoshimitsu T, et al. Dialysis-related hypotension as a cause of progressive frontal lobe atrophy in chronic hemodialysis patients: a 3-year prospective study. Nephron ClinPract 2004; 97: c23-c30

[11] Kooman J, Basci A, Pizzarelli F, et al. European Best Practice Guidelines: guideline on hemodynamic instability. Nephrol Dial Transplant 2007; 22 (Suppl 2) ii22-ii44

[12] Daugirdas JT. Pathophysiology of dialysis hypotension: an update. Am J Kidney Diseases 2001; 38 (Suppl 4): S11-S17

[13] Rostoker G,Griuncelli M, Loridon C, Benmaadi A, Illouz E. Left-ventricular diastolic dysfunction as a risk factor for dialytic hypotension. Cardiology 2009; 114(2): 142-149

[14] Nishimura M, Takahashi H, Maruyama K, Ohtsuka K, Nanbu A, Hara K, Yoshimura M. Enhanced production of nitric oxide may be involved in acute hypotension during maintenace hemodialysis. Am J Kidney Diseases 1998; 31: 809-817

[15] Cases A, Esforzado N, Lario S, Vera M, Lopez-Pedret J, Rivera-Fillat F, Jimenez W. Increased plasma adrenomedullin levels in hemodialysis patients with sustained hypotension. Kidney Int 2000; 57: 664-670

[16] Raj DS, Vincent B, Simpson K, Sato E, Jones KL, Welbourne TC, Levi M, Shah V, Blandon P, Zager P, Robbins RA. Hemodynamic changes in hemodialysis: role of nitric oxide and endothelin. Kidney Int 2002; 61: 697-704

[17] Franssen CFM. Adenosine and dialysis hypotension. Kidney Int 2006; 69: 789-791

[18] Schreiber MJ. Clinical case-based approach to understanding intradialytic hypotension. Am J Kidney Dis 2001; 38 (Suppl 4)S37-S47 
[19] Emili S, Black NA, Paul RV, et al. A protocol-based treatment for intradialytic hypotension in hospitalized hemodialysis patients. Am J Kidney Dis 1999; 33: 1107-1114

[20] The SAFE study investigators. A comparison of albumin and saline for fluid resuscitation in the intensive care unit. New Engl J Med 2004; 350: 2247-2256

[21] Rostoker G,Griuncelli M, Loridon C, Bourlet T, IllouzE, Benmaadi A. A pilot study of routine colloid infusion in hypotension-prone dialysis patients unresponsive to preventive measures. J Nephrol 2011; 24(02): 208-217

[22] Rostoker G,Griuncelli M, Loridon C, Bourlet T, Illouz E, Benmaadi A. Modulation of oxidative stress and microinflammatory status by colloids in refractory dialytic hypotension. BMC Nephrol 2011; oct 20; 12 (1): 58

[23] Jardin F, Prost JF, Ozier Y, Margairaz A. Hemodialysis in septic patients: improvements in tolerance of fluid removal with concentrated albumin as the priming fluid. Crit Care Med 1982; 10: 650-652

[24] McLigeyo SO. Experience with the use of human albumin in renal patients at the Kenyatta National Hospital. East Afr Med J 1993; 70: 15-17

[25] Van Der Sande FM, Luik AJ, Kooman JP, et al. Effect of intravenous fluids on blood pressure course during hemodialysis in hypotension-prone patients. J Am SocNephrol 2000; 11: 550-555

[26] Sirtl C, Laubenthal H, Zumtobel V, Kraft D, Jurecka W. Tissue deposits of hydroxyethylstarch (HES) dose-dependent ant time-related. Br J Anaesth 1999; 82: 510-515

[27] www.afssaps.sante.fr: Hydroxyethylamidons: Enquêtenationale de Pharmacovigilance et décisions; 21 avril 1999

[28] Rodriguez M, Llach F, Pederson JA, Palma A. Changes in plasma oncotic pressure during isolated ultrafiltration.Kidney Int 1982; 21: 519-523

[29] Grocott MP, Hamilton MA. Resuscitation fluids. Vox Sang 2002; 82: 1-8

[30] Van Der Sande F, Kooman JP, Barendregt J, et al. Effect of intravenous saline, albumin or hydroxyethyl starch on blood volume during combined ultrafiltration and hemodialysis. J Am SocNephrol 1999; 10: 1303-1308

[31] Graziani G, Finazzi S, Mangiarotti R, Como G, Fedeli C, Oldani S, Morganti A, Badalamenti S. Different cardiovascular responses to hemodialysis-induced fluid depletion and blood pressure compliance. J Nephrol 2010; 23(01): 55-61

[32] Ritz E, Ruffmann K, Rambausek M, Mall G, Schmidli M. Dialysis hypotension - is it related to diastolic left ventricular malfunction?Nephrol Dial Transplant 1987; 2: 293-297

[33] Ritz E, Rambausek M, Mall G, Ruffmann K, Mandelbaum A. Cardiac changes in uremia and their possible relation to cardiovascular instability on dialysis. In Terminal 
renal failure: therapeutic problems, possibilities and potentials. ContribNephrol. Klinkmann H, Smeby LC (eds). Basel, Karger 1990; vol 78pp 221-229

[34] Punzengruber C, Wallner M. Doppler echocardiographic analysis of diastolic left ventricular function in dialysis patients and its relation to intradialytic hypotension. J of Mol Med 1989; 67: 826-832

[35] Kramer W, Wizemann V, Lämmlein G, Thormann J, Kindler M, Schlepper M, Schütterle G. Cardiac dysfunction in patients on maintenance hemodialysis: II Systolic and diastolic properties of the left ventricle assessed by invasive methods. ContrNephrol (Karger, Basel) 1986; 52: 110-124

[36] London G. Left ventricular alterations and end-stage renal disease. Nephrol Dial Transplant 2002; 17 (Suppl 1): 29-36

[37] Gaash WH, Zile MR. Left ventricular diastolic dysfunction and diastolic heart failure. Annu Rev Med 2004; 55: 373-394

[38] Arias M, Alonso A, Garcia-Rio F. Diastolic heart failure. N Engl J Med 2005; 352: 307-308

[39] Tomita M, Malhotra D, Dheenan S, Shapiro JI, Henrich WL, Santoro TJ. A potential role for immune activation in hemodialysis hypotension. Renal Failure 2001; 23: 637-649

[40] Bergamini S, Vandelli L, Bellei E et Al. Relationship of asymmetric dimethylarginine to haemodialysis hypotension. Nitric Oxide 2004; 11: 273-278

[41] CantinAM, Paquette B, Richter M, Larivée P. Albumin-mediated regulation of cellular glutathione and nuclear factor kappa B activation. Am J RespCrit Care Med 2000; 162: 1539-1546

[42] Alam HB, Stanton K, Koustova E, Burris D, Rich N, Rhee P. Effects of different resuscitation strategies on neutrophil activation in a swine model of hemorrhagic shock. Resuscitation 2004; 60: 91-99.

[43] Harper SJ, Tomson CRV, Bates DO. Human uremic plasma increases microvascular permeability to water and proteins in vivo. Kidney Int 2002; 61: 1416-1422

[44] Evans TW. Albumin as a drug: biological effects on albumin unrelated to oncotic pressure. Aliment PharmacolTher 2002; 16(Suppl 5): 6-11

[45] Halliwell B. Free radicals, antioxidants and human disease: curiosity, cause or consequence? Lancet 1994; 344: 721-724

[46] Sandek A, Bjarnason I, Volkd HD, Crane R, Meddings JB, Niebauer J, Kaira PR, Buhner S, Herrmann R, Springer J, Doehner W, Von Haehling S, Anker SD, Rauchhaus M. Studies on bacterial endotoxin and intestinal absorption function in patients with chronic heart failure. Int J Cardiol 2012; 80-85

[47] Ritz E. Intestinal-renal syndrome: mirage or reality? Blood Purif 2011; 31: 70-76 
[48] McIntyre CW, Harrison LE, Eldehni MT, Jefferies HJ, Szeto CC, John SG, Sigrist MK, Burton JO, Hothi D, Korsheed S, Owen PJ, Lai KB, Li PK. Circulating endotoxemia: a novel factor in systemic inflammation and cardiovascular disease in chronic kidney disease. Clin J Am SocNephrol 2011; 6: 133-141

[49] Radi R, Bush KM, Cosgrove TP, Freeman BA. Reaction of xanthine oxidase-derived oxidants with lipid and protein of human plasma. Arch BiochemBiophys 1991: 286: 117-125

[50] Soejima A, Matsuzawa N, Miyake N et Al. Hypoalbuminemia accelerates erythrocyte membrane lipid peroxidation in chronic hemodialysis patients. ClinNephrol 1999; 51: 92-97

[51] Hu ML, Louie S, Cross CE, Motchnik P, Halliwell B. Antioxidant protection against hypochlorous acid in human plasma. J Lab Clin Med 1993; 121: 257-262

[52] Quinlan GJ, Mumby S, Martin GS, Bernard GR, Gutteridge JM, Evans TW. Albumin influences total plasma antioxidant capacity favorably in patients with acute lung injury. Crit Care Med 2004; 32: 755-759

[53] Morena M, Delbosc S, Dupuy AM, Canaud B, Cristol JP. Overproduction of reactive oxygen species in end-stage renal disease patients: a potential component of hemodialysis-associated inflammation. Hemodialysis Int 2005; 9: 37-46 
